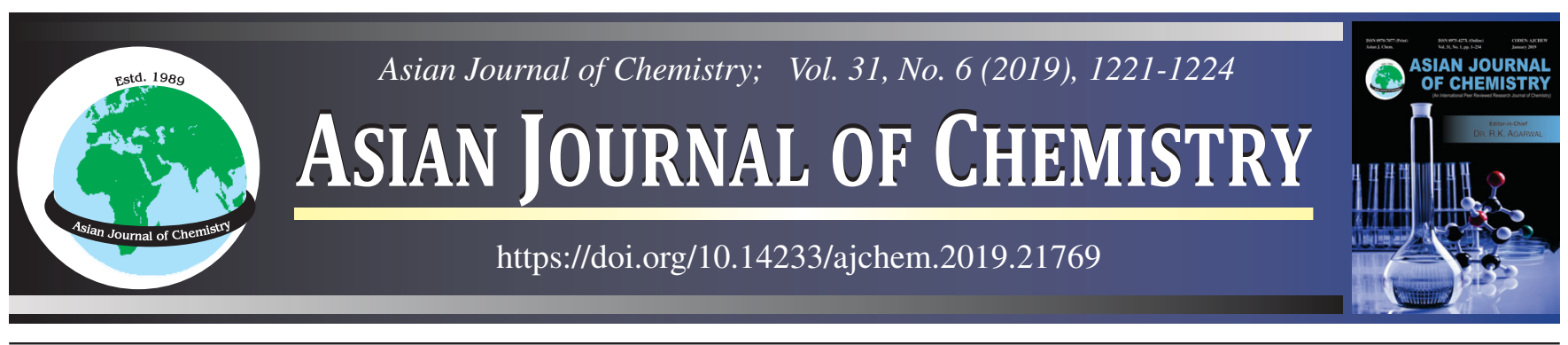

\title{
Chemically Modified Hydroxyapatite Nanocrystals by Temperature-Responsive Poly( $N$-isopropylacrylamide) via Surface Initiated Radical Polymerization
}

\author{
Doan Van Thuan ${ }^{1,2}$, Hieu-Vu Quang ${ }^{1,2}$, Bui Le Minh ${ }^{1,2}$, Pham Van Thinh $^{3}$, \\ Md. Rafiqul Islam ${ }^{4,5}$, Van Thi Thanh $\mathrm{Ho}^{6}$ and Duy Trinh NGUYeN ${ }^{7,8,9, *}$
}

${ }^{1}$ Institute of Applied Materials Science, Vietnam Academy of Science and Technology, Ho Chi Minh City, Vietnam ${ }^{2}$ NTT Hi-Tech Institute, Nguyen Tat Thanh University, Ho Chi Minh City, Vietnam

${ }^{3}$ Dong Nai Technology University, Bien Hoa City, Dong Nai Province, Vietnam

${ }^{4}$ Energy and Mineral Resources Division, Ministry of Power, Energy and Mineral Resources, Government of the People's Republic of Bangladesh,

Bangladesh

${ }^{5}$ Department of Imaging System Engineering, Pukyong National University, Busan, 608-737, Republic of Korea

${ }^{6}$ Hochiminh University of Natural Resources and Environment, Ho Chi Minh City, Vietnam

${ }^{7}$ Graduate University of Science and Technology, Vietnam Academy of Science and Technology, Hanoi, Vietnam

${ }^{8}$ Institute of Chemistry, Vietnam Academy of Science and Technology, Hanoi, Vietnam

${ }^{9}$ Center of Excellence for Functional Polymers and Nano Engineering, Nguyen Tat Thanh University, Ho Chi Minh City, Vietnam

*Corresponding author: Tel: +84 283 9404043; E-mail: ndtrinh@ntt.edu.vn

Received: 20 October 2018;

Accepted: 20 December 2018;

Published online: 29 April 2019;

AJC-19358

\begin{abstract}
This article reports on application of surface-initiated thiol-lactam initiated radical polymerization (TLIRP) method to modify hydroxyapatite nanocrystals (HAP) with thermoresponsive poly( $N$-isopropylacrylamide) (PNIPAm) brushes through grafting from strategy. Initially, 3-mercaptopropyl trimethoxysilane possessing thiol groups was functionalized with the -OH species on the surface of hydroxyapatite through ligand-exchanging response to introduce thiol species on hydroxyapatite (hydroxyapatite-thiol). Subsequently, attaching polymerization of $\mathrm{N}$-isopropylacrylamide from HAP-SH surface was accomplished in the attendance of butyrolactam to produce PNIPAAm$g$-HAP. Thermogravimetric analysis, Fourier transform infrared, X-ray photoelectron spectroscopy and their thermal phase transition behaviour were employed to confirm the grafting and to characterize the nanoparticle structure.
\end{abstract}

Keywords: Hydroxyapatite nanocrystals, Poly( $N$-isopropylacrylamide), Surface initiated radical polymerization.

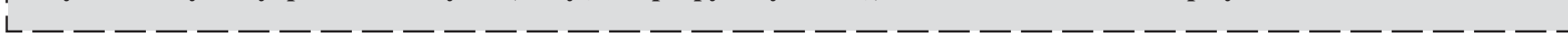

\section{INTRODUCTION}

In previous years, researchers have focused on the synthesis of smart surface materials with new features applicable in biological functional materials, medication transfer systems, biochemistry, bioelectronics, regenerative medicine, hybrid materials and surfaces [1-7]. One of such materials is polymeric nanomaterials. Nanoscale polymers, unlike bulk polymers, possess the structure with dimensions of nanoscale, which is less than $1000 \mathrm{~nm}$ in size, and therefore comprehend greatly increased surface area to volume ratio. This affords the material superior and unique properties utilizable in filtration, surface coatings, drug delivery, nanoreactors and catalysis [8-10]. Functional polymers are components for nano-fabrication and technology of surfaces due to their reaction in structure and extent for environment alterations. It is an appealing opinion to functionalize nanoparticles with stimuli-reaction $\operatorname{poly}(N-$ isopropylacrylamide) (PNIPAm) and the achieved materials has increased exponentially because of their enormous potential in biotechnology and medicine such as enzyme immobilization cell sorting, protein adsorption and drug delivery. $\operatorname{Poly}(N$-isopropylacrylamide) (PNIPAm) is a thermoresponsive polymer, showing a lower critical solution temperature at $\sim 32{ }^{\circ} \mathrm{C}$ [11-14].

The development of nanomaterials and biomaterials has considered colloidal inorganic nanometer-sized particles (nanoparticles) and nanocrystals as critical components [15-17]. Hydroxyapatite nanocrystals (HAP), with great chemical and structural likeness to native bone minerals in composition, crystallinity, and structure, exhibits superior mechanical property and unique osteoconductive function [18-24]. Upto now, modi-

This is an open access journal, and articles are distributed under the terms of the Creative Commons Attribution-NonCommercial-ShareAlike 4.0 (CC BY-NC-SA 4.0) International License which allows readers to freely read, download, copy, distribute, print, search, or link to the full texts of its articles and to use them for any other lawful non-commercial purpose as long as the original source is duly acknowledged. 
fication of the surface features of hydroxyapatite nanocrystals was carried out using a variety of techniques. Consequently, improvement of surface adhesion of HAP nanocrystals was performed through a chemical reaction with -OH species on the surface. This method is done through the reaction between the HAP nanoparticles with binding agents and polymers [25-27]. Nevertheless, to perform the above reaction, HAP must contain the -OH species on the surface and experienced some chemical reaction steps for attaching the polymers.

For preparation of polymeric biomaterials of nanoscale, radical polymerization technique has been widely applied [2832]. However, the conventional techniques are unable to produce the polymer structure with well-defined composition, architecture and functionality. Therefore, recent progress has been focused on the development of controlled/living radical polymerizations with the suggestion of new polymerization methods including metal-catalyzed living radical polymerizations, reversible addition fragmentation chain transfer (RAFT) polymerization, nitroxide mediated radical polymerization (NMRP) and atom transfer radical polymerization (ATRP) [33-38].

Recently, researchers used surface bonded -SH functionalized $\mathrm{SiO}_{2} / \mathrm{Fe}_{3} \mathrm{O}_{4} /$ carbon nanotubes and butyrolactam through thiol-lactam initiated radical polymerization (TLIRP) method. This process displayed a grafting for the creation of inorganic/ polymer nanocomposites materials [39-42]. The thiol-lactam initiated radical polymerization (TLIRP) protocol can suffer a vast region of response states and its free from metal contamination, so TLIRP protocol was easy and effective functional process for the surface alteration of nanoparticles. In this research, a fresh and convenient synthetic method is required for the preparation of new nanohybrid materials in which thermoresponsive PNIPAm are attached on the HAP nanocrystals by a surface initiated TLIRP method. The texture and morphology of (3-mercaptopropyl)trimethoxysilane (MPTMS) surface altered and PNIPAm grafted hydroxyapatite nanocrystals was generally studied by methods FT-IR, XPS, TGA studies and their thermal phase transition behaviour.

\section{EXPERIMENTAL}

$\mathrm{N}$-isopropylacrylamide (NIPAm) was dried by using vacuum drying and precipitated in hexane. All the chemicals used were provided by Aldrich. Hydroxyapatite (HAP) nanocrystals, (3mercaptopropyl)trimethoxysilane (MPTMS), butyrolactam and all solvents were used as introduced.

Immobilization of thiol groups onto hydroxyapatite nanocrystals (HAP-SH): In a classic process, HAP nanocrystals ( $4 \mathrm{~g}$ ) were modified by $1 \mathrm{~mL}$ (3-mercaptopropyl)trimethoxysilane (MPTMS) in a mixture of $180 \mathrm{~mL}$ ethanol and $20 \mathrm{~mL}$ water. The mixture was then stirred for $360 \mathrm{~min}$. Separation of the nanoparticles took place by centrifugation and sterile distilled water was used to wash nanoparticles multiple times. Following the separation of residue, the nanoparticles were removed water at $35^{\circ} \mathrm{C}$ to improve the steadiness of the covering and cured at $100^{\circ} \mathrm{C}$ for 1 day for the condensed silane to collect on the outer.

Synthesis of PNIPAm- $g$-HAP nanocomposites via surface initiated TLIRP: $0.2 \mathrm{~g}$ of HAP-SH; $2.0 \mathrm{~g}$ of MMA;
$0.8 \mathrm{~g}$ of butyrolactam (BL) and $4 \mathrm{~mL}$ of deionized and a Tefloncovered propulsion rod were put in a $50 \mathrm{~mL}$ circle bottle decorated with a restore condenser. The bottle was washed with nitrogen, heated to $80^{\circ} \mathrm{C}$ and stirred continuously. At the end of desired period, the bottle temperature was reduced to $35^{\circ} \mathrm{C}$ and excess diethyl ether was used to precipitate the reaction blend. Residue was removed from the product, which was then dehydrated by a vacuum oven. Toluene was used to reduce the concentration of product and free polymer attached hydroxyapatite from the unconnected polymer, which was finally centrifuged to collect PNIPAm- $g$-HAP nanocomposites.

The changes in chemical bonding on the surface of PNIPAm$g$-HAP hybrid nanoparticles were investigated by BOMEM Hartman \& Braun Fourier transformed infrared spectrophotometry spectrometer. The surface ingredient was analyzed using X-ray photoelectron spectroscopy (Thermo VG Multilab 2000) in extreme superior vacuum with $\mathrm{Al} \mathrm{K} \alpha$ radiation. PerkinElmer Pyris 1 analyzer (USA) is used for thermogravimetric analysis. The optical transmittance of PNIPAm- $g$-HAP aqueous dispersion was measured on a Perkin-Elmer Lambda 40 ultraviolet-visible spectrophotometer.

\section{RESULTS AND DISCUSSION}

Fig. 1 displayed analysis of FT-IR spectra of HAP-SH, HAP nanocrystals and PNIPAm- $g$-HAP nanocomposites. When compared with the spectra of bare HAP nanocrystals, a new weak band in the spectra of HAP-SH at $3000-2900 \mathrm{~cm}^{-1}$ is appeared because of the aliphatic $\mathrm{C}-\mathrm{H}$ stretching of $\mathrm{CH}_{3}-$ and $\mathrm{CH}_{2}$ - species of MPTMS residues. As shown in Fig. 1C, we can confirmed the amide I strip at $1647 \mathrm{~cm}^{-1}$ and amide II strips at $1536 \mathrm{~cm}^{-1}$, can be assigned $\mathrm{C}=\mathrm{O}$ stretching and $\mathrm{N}-\mathrm{H}$ stretching, respectively. The subsistence of two strips at 1369 and $1390 \mathrm{~cm}^{-1}$ with nearly equal intensity are nominated for the deformation of two $-\mathrm{CH}_{3}$ species on 1-methoxymethyl. Therefore, FT-IR analysis confirmed the permanence of thermoresponsive PNIPAm on the surface of HAP nanocrystals.

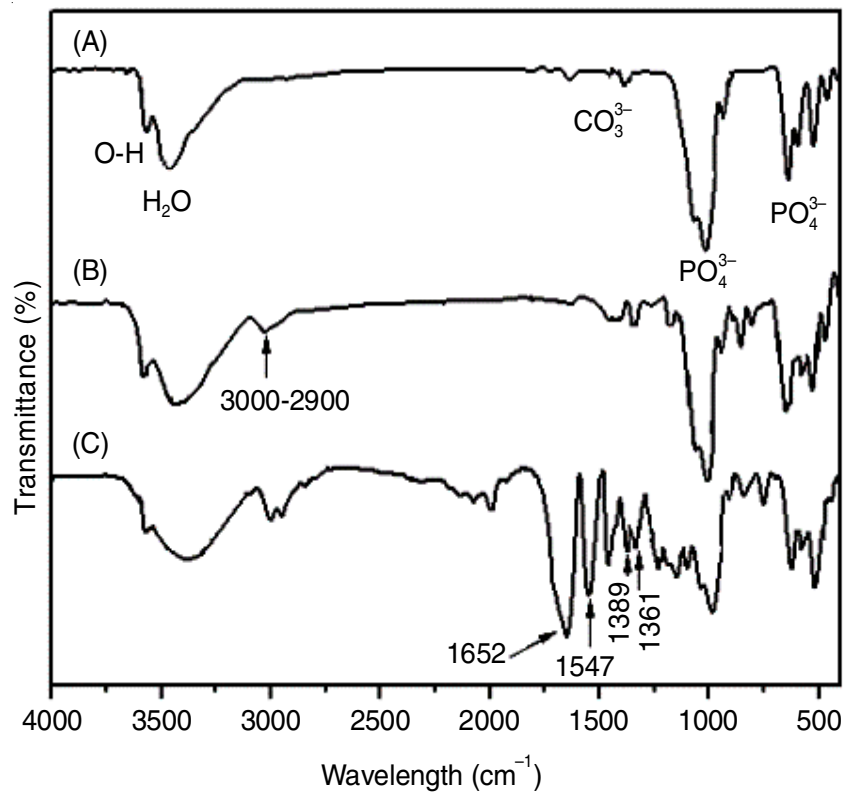

Fig. 1. FT-IR spectra of (A) HAP nanocrystals, (B) HAP-SH and (C) PNIPAm- $g$-HAP nanocomposites 
The surface chemical structure of PNIPAm- $g$-HAP nanocomposites was studied through XPS analysis, the XPS results are shown in Fig. 2. The results show the N1s and C1s have peaks at 400.1 and $285.1 \mathrm{eV}$, respectively. This indicated that PNIPAm series has attached to the surface of HAP nanocrystals substrate. In addition, peaks of Ca2p, P2s and P2p was recognized. This can be explained by exposure of HAP at the bottom. Besides, S2p signal was recognized. This can be explained as the presence of the $\mathrm{S}$ species at series heads and can perform as the evidence of living characterization.

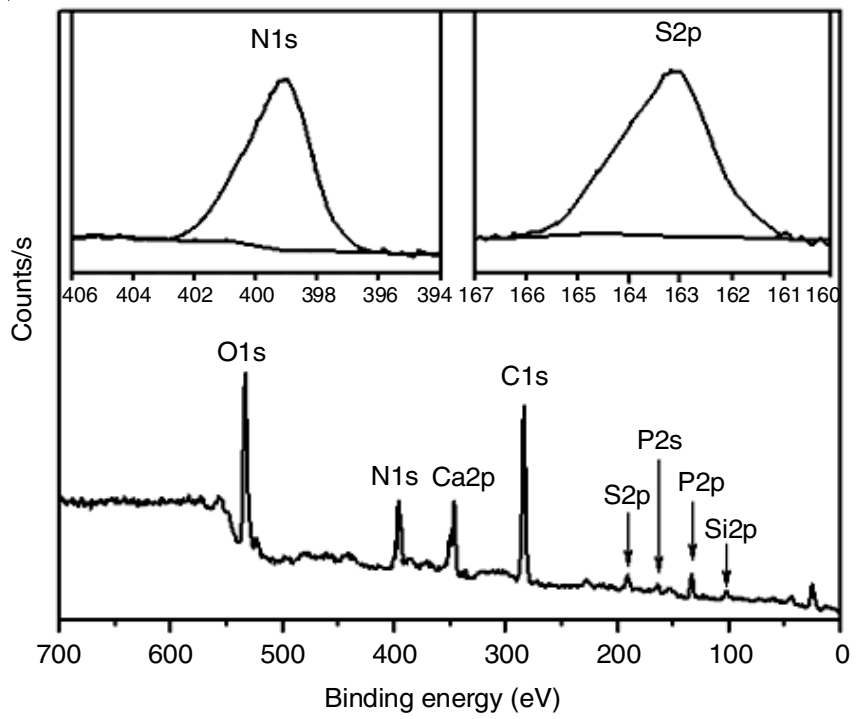

Fig. 2. XPS survey spectra of PNIPAm-g-HAP nanocomposites

Thermogravimetric analysis revealed the quantity of polymer attached to the surface of HAP nanocrystals. These polymer grafts played a significant role in getting better the mechanical features of nanocomposites. As shown in Fig. 3A, the fully dried HAP nanocrystals demonstrated a weight loss of $1.9 \%$ up to $800^{\circ} \mathrm{C}$ because of the removal of aqua molecules adsorbed on the outer and the liberation of textured aqua caused from the bonded $-\mathrm{OH}$ species. With the temperature ranging from 50 to $800{ }^{\circ} \mathrm{C}$, the weight decline of HAP-SH is estimated to be about $6.2 \%$ (Fig. 3B). According to TGA curve of PNIPAm$g$-HAP nanocomposites as shown in Fig. 3C, there is about $44.5 \%$ weight ascribed to loss of polymer PNIPAm chains.

The physical and chemical features of PNIPAm can change in the lower critical solution temperature (LCST) area and has been capitalized to formulate thermal responsive interfaces. At the concentration of $0.5 \mathrm{mg} / \mathrm{mL}$, the water solution of PNIPAm- $g$-HAP nanocomposites was measure uv-vis absorption spectra at wavelength $\lambda=800 \mathrm{~nm}$. Fig. 4 displays that the change of temperature leads to the transmission of PNIPAm- $g$-HAP suspension system in the aqua is also changes. The polymer PNIPAm brushes on the surface of HAP nanocrystals still keep on hydrophilic and the series of polymers are lengthened and became larger in water solution at a lower temperature. As the temperature rises, the structure of polymer PNIPAm began to break down and made condensed on the surface of HAP nanocrystals, and PNIPAm coatings evolve into hydrophobic coatings, decreasing their water solubility. Thus, HAP nanocrystals have a collection propensity, as demons-

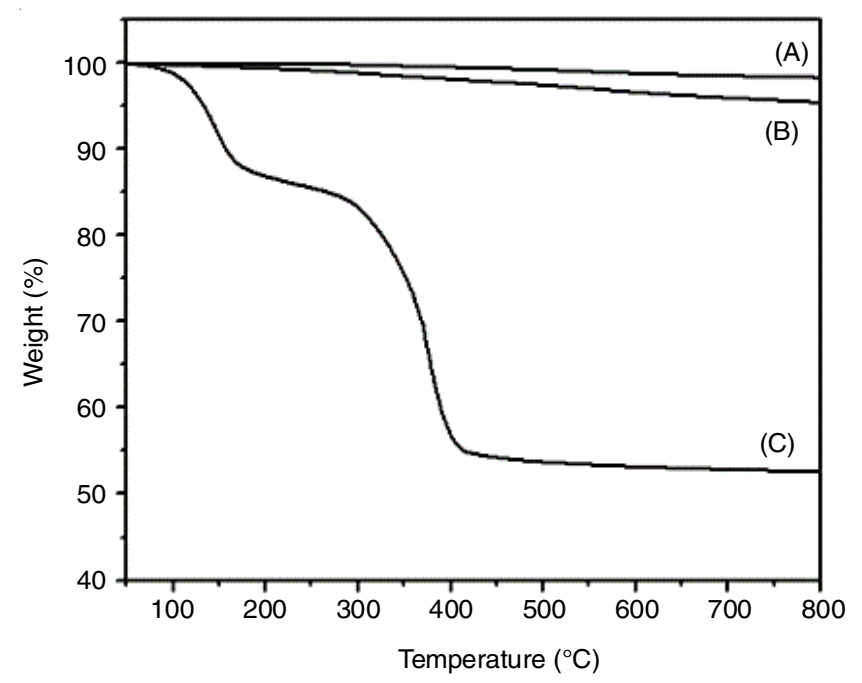

Fig. 3. TGA curves of (A) HAP nanocrystals, (B) HAP-SH and (C) PNIPAm- $g$-HAP nanocomposites

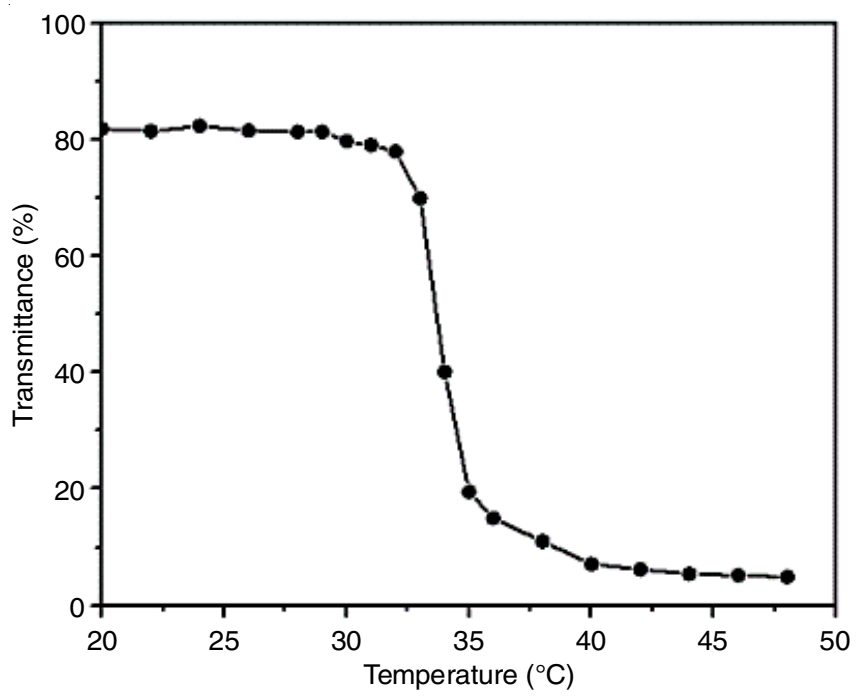

Fig. 4. Transmittance changes of PNIPAm- $g$-HAP nanocomposites in aqueous solution with temperature

trated by the fast transmittance in the graph. The results accentuated reversible thermal stimuli responsive properties of the material and the role of polymer quantity attached on the nanocrystal surface in giving nanocomposites prominent mechanical features. It is expected that this chemically immobilized thermoresponsive nanocomposites would have versatile applications in materials science as well as in nanobiotechnology.

\section{Conclusion}

A simple and efficient post-modification method for preparation of smart hybrid hydroxyapatite nanocrystals with a stimuli-responsive nanoshell based on surface-initiated thiollactam initiated radical polymerization (TLIRP) technique for the first time. The as-synthesized hybrid hydroxyapatite nanocrystals with a thermo-responsive poly( $N$-isopropylacrylamide) (PNIPAm) were actuated by FT-IR, XPS, TGA method. The UV transmittance spectra of PNIPAm- $g$-HAP nanocomposites in aqueous solution demonstrates that PNIPAm- $g$-HAP possess reversible thermal stimuli responsive properties. Hybrid hydroxyapatite gel interpenetrated with thermosen- 
sitive PNIPAm hydrogel has been advanced for controlled drug release. This method also shows a sustained favourable thermosensitive release profile provided that the temperature was kept higher than the lower critical solution temperature. This study demonstrates that PNIPAm- $g$-HAP nanohybrid materials will have promising applications in controlled drug delivery.

\section{ACKNOWLEDGEMENTS}

This work was supported by Institute of Applied Materials Science, Vietnam Academy of Science and Technology, Ho Chi Minh City, Vietnam and Pukyong National University, Republic of Korea

\section{CONFLICT OF INTEREST}

The authors declare that there is no conflict of interests regarding the publication of this article.

\section{REFERENCES}

1. B. Lebeau and P. Innocenzi, Chem. Soc. Rev., 40, 886 (2011); https://doi.org/10.1039/C0CS00106F.

2. L.G. Bach, M.R. Islam, X.T. Cao, J.M. Park and K.T. Lim, J. Alloys Compd., 582, 22 (2014);

https://doi.org/10.1016/j.jallcom.2013.07.186.

3. A.K. Nguyen, T.H. Nguyen, B.Q. Bao, L.G. Bach and D.H. Nguyen, Int. J. Biomater, 2018, Article ID 1575438 (2018); https://doi.org/10.1155/2018/1575438.

4. P.J. Molino and G.G. Wallace, APL Mater., 3, 014913 (2015); https://doi.org/10.1063/1.4905372.

5. O. Baranov, I. Levchenko, J.M. Bell, J.W.M. Lim, S. Huang, L. Xu, B. Wang, D.U.B. Aussems, S. Xu and K. Bazaka, Mater. Horizons, 5, 765 (2018);

https://doi.org/10.1039/C8MH00326B.

6. B.Q. Bao, N.H. Le, D.H.T. Nguyen, T.V. Tran, L.P.T. Pham, L.G. Bach, H.M. Ho, T.H. Nguyen and D.H. Nguyen, Mater. Sci. Eng. C, 91, 912 (2018);

https://doi.org/10.1016/j.msec.2018.07.008.

7. H. Liu, Y. Wang, J. Huang, Z. Chen, G. Chen and Y. Lai, Adv. Funct. Mater., 28, 1707415 (2018);

https://doi.org/10.1002/adfm.201707415.

8. A. Alam, Y. Zhang, H.C. Kuan, S.H. Lee and J. Ma, Prog. Polym. Sci., 77, 1 (2018); https://doi.org/10.1016/j.progpolymsci.2017.09.001.

9. L.G. Bach, B.T.P. Quynh, M.R. Islam and K.T. Lim, J. Nanosci. Nanotechnol., 16, 12856 (2016); https://doi.org/10.1166/jnn.2016.13651.

10. M.S. Bakshi, Adv. Colloid Interface Sci., 256, 101 (2018); https://doi.org/10.1016/j.cis.2018.04.012.

11. O.N. Ciocoiu, G. Staikos and C. Vasile, Carbohydr. Polym., 184, 118 (2018); https://doi.org/10.1016/j.carbpol.2017.12.059.

12. L. Tan, B. Liu, K. Siemensmeyer, U. Glebe and A. Böker, J. Colloid Interface Sci., 526, 124 (2018); https://doi.org/10.1016/j.jcis.2018.04.074.

13. L.J. Luo, C.C. Huang, H.C. Chen, J.Y. Lai and M. Matsusaki, Carbohydr. Polym., 197, 375 (2018); https://doi.org/10.1016/j.carbpol.2018.06.020.

14. K. Nagase, T. Okano and H. Kanazawa, Nano-Structures \& Nano-jects, 16, 9 (2018); https://doi.org/10.1016/j.nanoso.2018.03.010.

15. M. Rizwan, G. Mujtaba, S.A. Memon, K. Lee and N. Rashid, Renew. Sustain. Energy Rev., 92, 394 (2018); https://doi.org/10.1016/j.rser.2018.04.034.

16. M. Hagemann and W.R. Hess, Curr. Opin. Biotechnol., 49, 94 (2018); https://doi.org/10.1016/j.copbio.2017.07.008

17. V.A. Risso, J.M. Sanchez-Ruiz and S.B. Ozkan, Curr. Opin. Struct. Biol., 51, 106 (2018); https://doi.org/10.1016/j.sbi.2018.02.007.
18. D. Tsiourvas, A. Tsetsekou, M.I. Kammenou and N. Boukos, Mater. Sci. Eng. C, 58, 1225 (2016); https://doi.org/10.1016/j.msec.2015.09.076.

19. M. Okada and T. Furuzono, Mater. Sci. Eng. B, 173, 199 (2010); https://doi.org/10.1016/j.mseb.2009.12.009.

20. L.G. Bach, M.R. Islam and K.T. Lim, Mater. Lett., 93, 64 (2013); https://doi.org/10.1016/j.matlet.2012.11.051.

21. L.G. Bach, M.R. Islam, T.S. Vo, S.K. Kim and K.T. Lim, J. Colloid Interface Sci., 394, 132 (2013);

https://doi.org/10.1016/j.jcis.2012.11.068.

22. F. Mohandes, M. Salavati-Niasari, M. Fathi and Z. Fereshteh, Mater. Sci. Eng. C, 45, 29 (2014); https://doi.org/10.1016/j.msec.2014.08.058.

23. P. Wei, B. Wang, X. Lu, R. Xin and F. Ren, Surf. Coat. Technol., 313, 381 (2017); https://doi.org/10.1016/j.surfcoat.2017.01.108.

24. L.G. Bach, B.T.P. Quynh and V.T.T. Ho, J. Nanosci. Nanotechnol., 17, 4127 (2017); https://doi.org/10.1166/jnn.2017.13381.

25. L.G. Bach, B.T.P. Quynh, K.K. Kiet, M.R. Islam and K.T. Lim, J. Nanosci. Nanotechnol., 16, 8814 (2016); https://doi.org/10.1166/jnn.2016.12510.

26. A. Sobczak-Kupiec, K. Pluta, A. Drabczyk, M. W³oœ and B. Tyliszczak, Ceram. Int., 44, 13630 (2018); https://doi.org/10.1016/j.ceramint.2018.04.199.

27. J. Chen, M. Liu, Q. Huang, R. Jiang, H. Huang, F. Deng, Y. Wen, J. Tian, X. Zhang and Y. Wei, Mater. Sci. Eng. C, 92, 518 (2018); https://doi.org/10.1016/j.msec.2018.06.054.

28. N. Ballard and J.M. Asua, Prog. Polym. Sci., 79, 40 (2018); https://doi.org/10.1016/j.progpolymsci.2017.11.002.

29. X. Wang, L. Shen and Z. An, Prog. Polym. Sci., 83, 1 (2018); https://doi.org/10.1016/j.progpolymsci.2018.05.003.

30. X.T. Cao, L.G. Bach, M.R. Islam and K.T. Lim, Mol. Cryst. Liq. Cryst., 618, $111(2015)$; https://doi.org/10.1080/15421406.2015.1076305.

31. L.G. Bach, X.T. Cao, B.T.P. Quynh, V.T.T. Ho and K.T. Lim, Mol. Cryst. Liq. Cryst., 644, 183 (2017); https://doi.org/10.1080/15421406.2016.1277478.

32. C.M.Q. Le, X.T. Cao, L.G. Bach, W.K. Lee, I. Kang and K.T. Lim, Mol. Cryst. Liq. Cryst., 660, 143 (2018); https://doi.org/10.1080/15421406.2018.1456136.

33. M.A. Söylemez, O. Güven and M. Barsbay, Eur. Polym. J., 103, 21 (2018); https://doi.org/10.1016/j.eurpolymj.2018.03.037.

34. X. Chen, X. Liu, C. Miao, P. Song and Y. Xiong, Eur. Polym. J., 107, 229 (2018); https://doi.org/10.1016/j.eurpolymj.2018.08.016.

35. L.G. Bach, Q.T.P. Bui, X.T. Cao, V.T.T. Ho and K.T. Lim, Polym. Bull., 73, 2627 (2016); https://doi.org/10.1007/s00289-016-1712-5.

36. J. Ran, L. Wu, Z. Zhang and T. Xu, Prog. Polym. Sci., 39, 124 (2014); https://doi.org/10.1016/j.progpolymsci.2013.09.001.

37. P. Polanowski, K. Halagan, J. Pietrasik, J.K. Jeszka and K. Matyjaszewski, Polymer, 130, 267 (2017); https://doi.org/10.1016/j.polymer.2017.10.011

38. F. Lorandi, M. Fantin, A.A. Isse and A. Gennaro, Curr. Opin. Electrochem., 8, 1 (2018); https://doi.org/10.1016/j.coelec.2017.11.004.

39. L.G. Bach, M.R. Islam, J.T. Kim, S.Y. Seo and K.T. Lim, Appl. Surf. Sci., 258, 2959 (2012); https://doi.org/10.1016/j.apsusc.2011.11.016.

40. L.G. Bach, X.T. Cao, V.T.T. Ho, M.R. Islam and K.T. Lim, Mol. Cryst. Liq. Cryst., 618, 120 (2015); https://doi.org/10.1080/15421406.2015.1076315.

41. H.S. Hwang, J.H. Bae, H.G. Kim and K.T. Lim, Eur. Polym. J., 46, 1654 (2010); https://doi.org/10.1016/j.eurpolymj.2010.06.008.

42. M.H. Rashid, J.H. Bae, C. Park and K.T. Lim, Mol. Cryst. Liq. Cryst., 532, 514 (2010); https://doi.org/10.1080/15421406.2010.497039. 